\title{
Diagnostic Value of Different Biomarkers to Identify Bacterial Coinfection in Vietnamese Children with Severe Rhinovirus Pneumonia
}

\author{
Hien Thu Pham ${ }^{1}$ Tran Thi Ngoc Nguyen ${ }^{2}$ Ngo Thi Tamº \\ ${ }^{1}$ Department of International Outpatient, National Children's \\ Hospital, Hanoi, Vietnam \\ 2 Respiratory Center, National Children's Hospital, Hanoi, Vietnam \\ ${ }^{3}$ Faculty of Health Sciences, Thang Long University, Hanoi, Vietnam \\ Address for correspondence Tran Thi Ngoc Nguyen, PhD, Respiratory \\ Center, National Children's Hospital, Hanoi, Vietnam \\ (e-mail: dr.ngoctran259@yahoo.com.vn).
}

J Child Sci 2020;10:e25-e31.

\begin{abstract}
Keywords

- respiratory syncytial virus

- pneumonia

- procalcitonin

- bacterial coinfections

This study aims to assess the diagnostic value of high-sensitivity C-reactive protein (hsCRP), procalcitonin (PCT), and interleukin (IL)- 6 in the diagnosis of pneumonia caused by Rhinovirus alone or with bacterial coinfection in Vietnamese children under 5 years of age. A cross-sectional study was conducted on 26 children under 5 years of age with severe pneumonia due to Rhinovirus at the National Pediatric Hospital. IL-6, hs-CRP, and PCT tests were performed. The diagnostic values of PCT, IL- 6 , and hs-CRP in classifying those with viral alone and those with bacterial coinfection were determined. Of 26 children, 10 children were diagnosed to have bacterial coinfections (38.5\%). The optimal cutoff point for PCT was $>2.30 \mathrm{ng} / \mathrm{mL}$ (sensitivity $50 \%$, specificity $94 \%$, positive predictive value $83 \%$, and negative predictive value $75 \%$ ). The optimal cutoff point for hs-CRP was $>1.53 \mathrm{mg} / \mathrm{dl}$ (sensitivity $90 \%$, specificity $56 \%$, positive predictive value $56 \%$, and negative predictive value $90 \%$ ). Finally, the optimal cut-off point for IL-6 was $>441.5 \mathrm{pg} / \mathrm{mL}$ (sensitivity $20 \%$, specificity $100 \%$, positive predictive value $100 \%$, and negative predictive value $60 \%$ ). The accuracy rate of PCT was the highest with $69.2 \%$, followed by hs-CRP with $65.4 \%$. Inflammatory biomarkers such as PCT and hsCRP were able to distinguish children with severe pneumonia caused by Rhinovirus alone and those with bacterial coinfection.
\end{abstract}

\section{Introduction}

Rhinovirus is a leading cause of respiratory infection in children, accounting for approximately 20 to $50 \%{ }^{1-4}$ Rhinovirusrelated pneumonia may be asymptomatic, but this virus may worsen respiratory infection or cause outbreaks. ${ }^{5-8}$ Rhinovirus infection causes severe consequences for hospitalized children, similar to infection caused by respiratory syncytial virus or influenza viruses. ${ }^{9}$ During a severe outbreak of acute respiratory infections in Vietnam caused by Rhinovirus, the mortality rate of hospitalized children was $58.3 \% .{ }^{8}$ Rhinovirus also causes a significant burden on resources, costs, and health in children with acute respiratory failure. ${ }^{10-12}$

received

March 9, 2020

accepted

May 8, 2020
DOI https://doi.org/ 10.1055/s-0040-1713362. ISSN 2474-5871.
The rate of bacterial coinfection in pediatric pneumonia caused by Rhinovirus is over $40 \% .^{13}$ Compared with patients with viral pneumonia alone, coinfected pneumonia patients had a higher rate of mechanical ventilation and death. ${ }^{13,14}$ Therefore, determining whether infants have coinfection is very important. ${ }^{15}$ Difficulties in confirming the diagnosis of viral pneumonia with or without bacterial coinfection also contribute to the increase in antibiotic resistance. ${ }^{16}$ Unfortunately, clinical features, routine tests, and X-ray results are not specific to distinguishing between viral or bacterial pneumonia. ${ }^{17-19}$ Isolating the pathogen directly for a comprehensive diagnosis in a patient is not feasible. ${ }^{16}$ However, recent studies have shown the advantages of using inflammatory biomarkers
Copyright (c) 2020 Georg Thieme Verlag License terms KG Stuttgart · New York 
such as IL-6, hs-CRP, and PCT, in the diagnosis of concurrent bacterial pneumonia. ${ }^{18,20-23}$

Although the figures show high rates of pneumonia in children and its burden ${ }^{24}$ in Vietnam, there is a lack of research related to identifying the methods to diagnose pneumonia with and without bacterial coinfection. This study aimed to assess the diagnostic value of hs-CRP, PCT, and IL- 6 in the diagnosis of pneumonia caused by Rhinovirus alone or bacterial coinfection in Vietnamese children under five years of age.

\section{Materials and Methods}

\section{Study Designs and Setting}

A cross-sectional study was conducted on children at the National Hospital of Pediatrics from January 2015 to March 2017. Twenty-six children under five years of age diagnosed with Rhinovirus severe pneumonia were included in this study. A child was determined to have severe pneumonia according to WHO 2013 standards when he or she had a cough or trouble breathing and had, at least, one of the following symptoms: 1 ) cyanosis or $\mathrm{SpO} 2<90 \%$; 2) severe respiratory distress; and 3 ) could not drink or vomit everything, coma or not awake, or convulsions. ${ }^{25}$ PCR tests were used to confirm Rhinovirus infection. We excluded children with congenital chronic diseases and those whose parents or guardians who did not agree to participate in the study. The study was approved by the institutional review board of Vietnam Military Medical University (Code 92/QD-HVQY).

\section{Variables and Measurement}

Physicians clinically examined all patients admitted to the hospital and asked their parents or guardians to report demographic, medical, and clinical characteristics. We collected $2 \mathrm{~mL}$ of venous blood from each child for biochemical tests. Quantification of biomarkers, including Hs-CRP, IL-6, and PCT, were also performed. Olympus AU 2700 was used to quantify Hs-CRP by turbidity measurement method. PCT concentration was determined by the luminescent immunization method, using Siemens ADVIA Centaur. Samples were placed in tubes with Li-Heparin and K3-EDTA or without anticoagulants before centrifugation. Biprad's Bio-Plex Protein Array System was used to quantify IL-6. The Vitek 2 machine was used to determine bacteria by identifying the chemical and biological properties of bacteria through the changing color of environmental wells. The minimum inhibitory concentration was measured to monitor the growth of bacteria. The system used visible light at the wavelengths of $660 \mathrm{~nm}, 568 \mathrm{~nm}, 428 \mathrm{~nm}$ showed off the environment wells, and then measured the blocked light intensity to identify the decrease in light intensity.

\section{Statistical Analysis}

We used STATA 15.0 software to analyze the data. Clinical and subclinical characteristics were compared between children with severe pneumonia caused by Rhinovirus with and without bacterial coinfection by the Mann-Whitney test and Chi-squared test. The receiver operating characteristic (ROC) was calculated to determine the diagnostic value of the HsCRP, IL-6, and PCT. Then, sensitivity, specificity, positive predictive value, negative predictive value, positive likelihood ratio $(L R+)$, negative likelihood ratio $(L R-)$, and accuracy rate of each diagnostic value were calculated. We used the Youden index to determine the optimal cutoff point. Statistical significance was determined if the $p$ value was less than 0.05 .

\section{Results}

-Fig. 1 shows that 10/26 children with severe pneumonia due to Rhinovirus have coinfection with bacteria, accounting for $38.5 \%$. The most common organisms for coinfection bacteria were Pseudomonas aeruginosa (four cases), Hemophilus influenza (three cases), Streptococcus pneumoniae (two cases), and Klebsiella pneumoniae (one case).

- Table 1 described that the average age was 8.6 months (standard deviation $[S D]=9.6$ ); $90 \%$ of children were under 24 months of age. The majority of research subjects were male, accounting for $73.1 \%$. Median values for white blood cells, PCT, Hs-CRP, and IL-6 were 8.9 (interquartile range $[\mathrm{IQR}]=7.8-16.7) \quad \mathrm{g} / \mathrm{dl} ; \quad 0.3 \quad(\mathrm{IQR}=0.04-1.2) \quad \mathrm{ng} / \mathrm{mL} ; 2.0$ $(\mathrm{IQR}=0.44-6.2) \mathrm{mg} / \mathrm{dl}$ and $\mathrm{pg} / \mathrm{mL}$, respectively. Patients with bacterial coinfection had significantly higher pulse rate and Hs-CRP concentrations than patients with Rhinovirus alone $(p<0.05)$. - Fig. 2 illustrated the difference between two groups regarding PCT, hs-CRP, and IL-6 values.

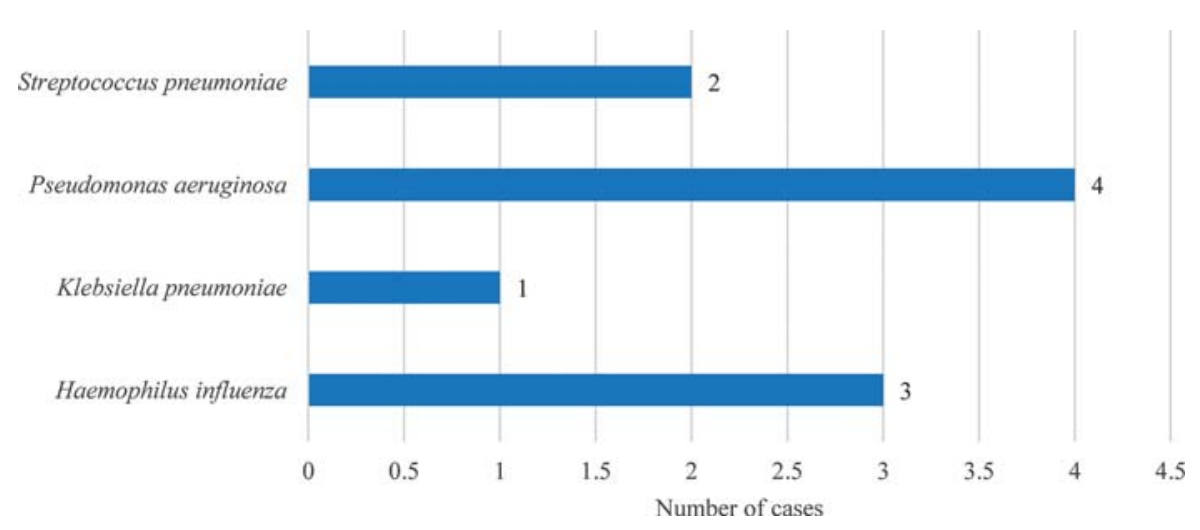

Fig. 1 Distribution of viral and bacterial pathogens in Rhinovirus pneumonia children with bacterial coinfections 
Table 1 Patients' characteristics between patients with Rhinovirus pneumonia alone and Rhinovirus pneumonia with viral and bacterial coinfection

\begin{tabular}{|c|c|c|c|}
\hline & Rhinovirus alone $(n=16)$ & $\begin{array}{l}\text { Rhinovirus with bacterial } \\
\text { coinfection }(n=10)\end{array}$ & $p$-value \\
\hline Age (months) (mean $\pm S D$ ) & $7.0 \pm 11.3$ & $7.4 \pm 6.9$ & 0.93 \\
\hline Male, n (\%) & $11(68.8)$ & $8(80.0)$ & 0.53 \\
\hline \multicolumn{4}{|l|}{ Clinical features } \\
\hline Fever & $9(56.3)$ & $8(80.0)$ & 0.22 \\
\hline Rapid pulse rate & $4(25.0)$ & $7(70.0)$ & 0.02 \\
\hline Runny nose & $4(25.0)$ & $2(20.0)$ & 0.77 \\
\hline Wheezing & $2(12.5)$ & $1(10.0)$ & 0.85 \\
\hline Diarrhea & $8(50.0)$ & $3(30.0)$ & 0.32 \\
\hline \multicolumn{4}{|l|}{ Vital signs (mean \pm SD) } \\
\hline Respiratory rate (/min) & $53.6 \pm 5.9$ & $51.1 \pm 7.8$ & 0.37 \\
\hline Pulse rate $(/ \mathrm{min})$ & $147.4 \pm 15.9$ & $160.7 \pm 17.7$ & 0.06 \\
\hline Body temperature $\left({ }^{\circ} \mathrm{C}\right)$ & $37.7 \pm 0.9$ & $37.5 \pm 0.7$ & 0.70 \\
\hline $\mathrm{SpO}_{2}$ & $90.1 \pm 3.2$ & $88.9 \pm 5.3$ & 0.47 \\
\hline \multicolumn{4}{|c|}{ Initial laboratory findings (median, IQR) } \\
\hline WBC $\left(\times 10^{3} / \mathrm{mm}^{3}\right)$ & $8.6(6.7-10.6)$ & $12(8.8-16.7)$ & 0.07 \\
\hline Lymphocyte (\%) & $4.6(3.7-5.7)$ & $5.5(4-7.4)$ & 0.27 \\
\hline PCT (ng/mL) & $0.2(0-0.9)$ & $1.6(0.1-3)$ & 0.07 \\
\hline $\mathrm{Hs}-\mathrm{CRP}(\mathrm{mg} / \mathrm{dl})$ & $0.8(0.3-4.7)$ & $5.6(1.7-14.4)$ & 0.02 \\
\hline $\mathrm{PaO}_{2}$ & $71.3(63-85)$ & 67.5 (62-69) & 0.62 \\
\hline IL-6 (pg/mL) & $4.1(1.2-6.8)$ & $3.1(0.6-4.7)$ & 0.58 \\
\hline Deaths after hospitalization, n (\%) & $1(7.7)$ & $0(0.0)$ & 0.45 \\
\hline
\end{tabular}

Abbreviations: hs-CRP, high-sensitivity C-reactive protein; IL-6, Interleukin-6; IQR, interquartile range; PCT, procalcitonin; SD, standard deviation; SpO2, oxygen saturation; WBC, white blood cell.

-Fig. 3 showed the ROC analysis results. The area under the curve (AUC) of the PCT, Hs-CRP and IL- 6 indicators was 0.716 (95\% CI $=0.498-0.933, p=0.053) ; 0.772$ (95\% CI $=0.590-$ $0.953, p=0.003)$; and $0.400(95 \% \mathrm{CI}=-0.01-0.807, p=0.63)$, respectively.

- Table 2 presented the diagnostic values of biomarkers. With the optimal cutoff point of $>2.30 \mathrm{ng} / \mathrm{mL}$, the diagnosis of bacterial infection by PCT gave $50 \%$ sensitivity, $94 \%$ specificity, $83 \%$ positive predictive value, and $75 \%$ negative predictive value. The optimal cutoff point for hs-CRP was $>1.53 \mathrm{mg} / \mathrm{dl}$ (sensitivity $90 \%$, specificity $56 \%$, positive predictive value $56 \%$, negative predictive value $90 \%$ ). Finally, the optimal limited for IL-6 is $\geq 441.5 \mathrm{pg} / \mathrm{mL}$ ( $20 \%$ sensitivity, $100 \%$ specificity, $100 \%$ positive predictive value, $60 \%$ negative predictive value). The accuracy rates of IL-6, hs-CRP, and PCT were 54.5\%, 65.4\%, and $69.2 \%$, respectively.

\section{Discussion}

Our study demonstrates that bacterial coinfections often present in children with severe pneumonia caused by Rhinovirus. This study also demonstrates the potential role of different inflammatory biomarkers, especially PCT and hs-
CRP, in the detection and classification of severe Rhinovirus pneumonia with and without concurrent bacterial infection.

Children with viral pneumonia may have either bacterial coinfection or secondary bacterial infection. The incidence of bacterial coinfection with Rhinovirus in the study was $38.5 \%$, which was similar to the rate in an earlier report by Hwa Sik Jung et al. (42.5\%). ${ }^{13}$ The bacteria such as Pseudomonas aeruginosa, Hemophilus influenza, Streptococcus pneumoniae, and Klebsiella pneumoniae were found in severe pneumonia patients in this study. Other studies reported other types of bacteria, such as Staphylococcus aureus, Chlamydia pneumoniae, Mycoplasma, etc., which might also be present in pediatric patients with severe Rhinovirus pneumonia. ${ }^{13,26}$ This difference might be likely due to the limited sample size in this study. The determination of bacterial coinfection in patients with severe Rhinovirus pneumonia is important in predicting the outcome and assisting in the development of the appropriate treatment plan. ${ }^{15,16}$

Fever, rapid pulse rate, runny nose, wheezing, and diarrhea are common clinical symptoms in both Rhinovirus patients with severe pneumonia with and without bacterial coinfection. These symptoms are also common in people with pneumonia due to other causes. ${ }^{27}$ Our study showed that the rapid pulse 

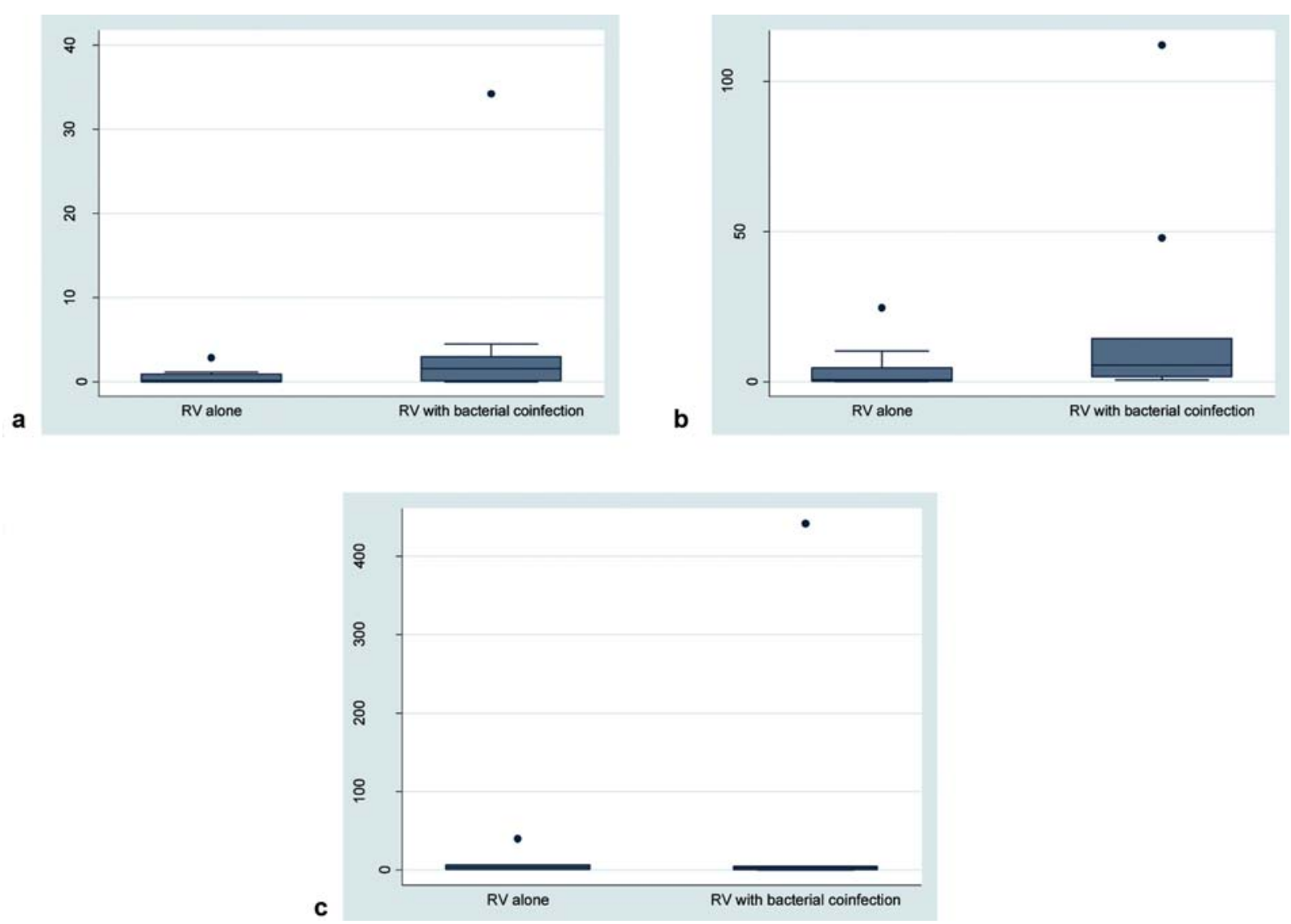

Fig. 2 Box plot of (a) PCT, (b) hs-CRP, and (c) IL-6 levels on initial hospital visit between Rhinovirus pneumonia alone and Rhinovirus pneumonia with bacterial coinfections. Abbreviations: hs-CRP, high-sensitivity C-reactive protein; IL-6, Interleukin-6; PCT, procalcitonin.

rate in children with bacterial coinfection was significantly higher than that in patients with Rhinovirus alone. Previous studies have also shown that tachycardia has a high-diagnostic value for identifying serious infections in children, ${ }^{28,29}$ while coinfection with bacteria increases the severity of the viral disease pneumonia. ${ }^{13,14}$ However, there has been no evidence that a rapid pulse rate can be used as a criterion to classify the cause of pneumonia. There was no clinical difference between children with Rhinovirus alone and bacterial coinfection. This result is consistent with previous literature that the clinical features are nonspecific to distinguish pneumonia agents. ${ }^{17-19}$

Recent evidence has shown the diagnostic effectiveness of biomarkers in distinguishing bacterial pneumonia from bacterial superinfection. ${ }^{18,20-23}$ Although prior study indicated a significant increase of IL-6 in experimental mice with cobacterial pneumonia, ${ }^{30}$ our research results show that IL-6 has poor diagnostic values with AUC of $0.400(95 \% \mathrm{CI}=-$ $0.01-0.807, p=0.63$ ). According to a study by Jaana Karhu et al, IL-6 is not different in groups of patients with bacterial, viral, or both pneumoniae. ${ }^{31}$

In this study, the CRP values were significantly higher among the coinfection group than others, which was similar to the results of previous reports. ${ }^{20,21,32-34}$ The optimal cutoff point for hs-CRP was $1.53 \mathrm{mg} / \mathrm{dl}$ (sensitivity 90\%, specificity 56\%), and the AUC for hs-CRP was 0.772 , indicating this diagnostic value was valid. Although some authors were arguing that CRP is not useful in distinguishing coin- fected bacterial infections in patients with Rhinovirus community pneumonia, ${ }^{26,35}$ other studies were confirming the ability to distinguish between viral and bacterial agents that cause pneumonia with CRP limit point $>0.8 \mathrm{mg} / \mathrm{dl} .^{36-38}$ Although controversies exist surrounding the use of the hs-CRP index to identify severe pneumonia caused by coinfection with the virus, this biomarker can still be used to support decisions about antibiotic use. The diagnostic value may be increased if hs-CRP is combined with other criteria. $^{21,33}$

Recent studies suggested that increased PCT was the result of bacterial infection, since PCT is a calcitonin precursor produced by transcription of the gene CALC -1 , which was activated to increase PCT production in the endocrine gland, and also epithelial when being bacterially infected. ${ }^{39}$ On the other hand, in a patient with viral infection alone, PCT only increases to a certain limit because the viral infection can cause a decrease in the induction of $\mathrm{PCT}^{20}$ The results also suggest that PCT has the potential to be a valuable diagnostic indicator to detect children with severe pneumonia caused by coinfection with the virus. The optimal limit is defined as PCT $>2.30 \mathrm{ng} / \mathrm{mL}$ for $50 \%$ sensitivity and $94 \%$ specificity. According to Hoshina et al, the limit was defined as PCT $>0.2 \mathrm{ng} / \mathrm{mL}$ with $86 \%$ sensitivity and $80 \%$ specificity when diagnosing pathogens with bacterial agents. ${ }^{40}$ Thomas reported about children with community-acquired pneumonia who also identified PCT $>0.07$ points with $48.7 \%$ sensitivity and $81.1 \%$ specificity. ${ }^{18}$ 


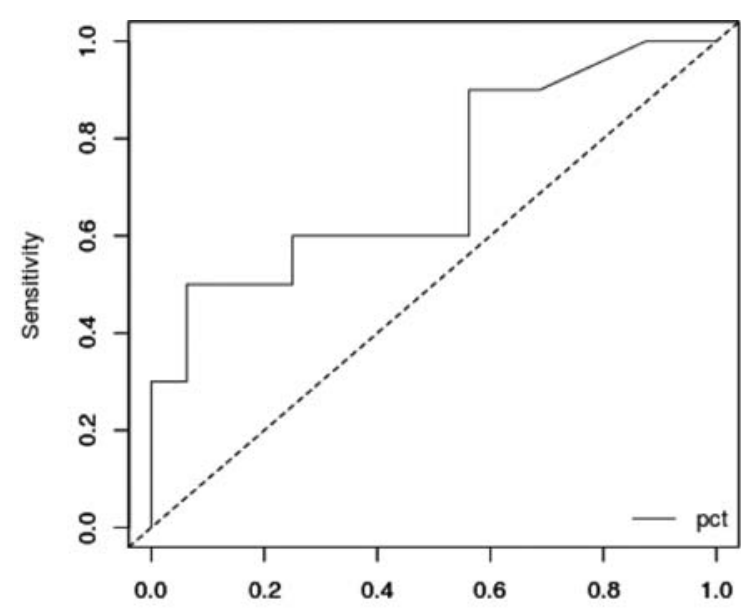

a 1-Specificity

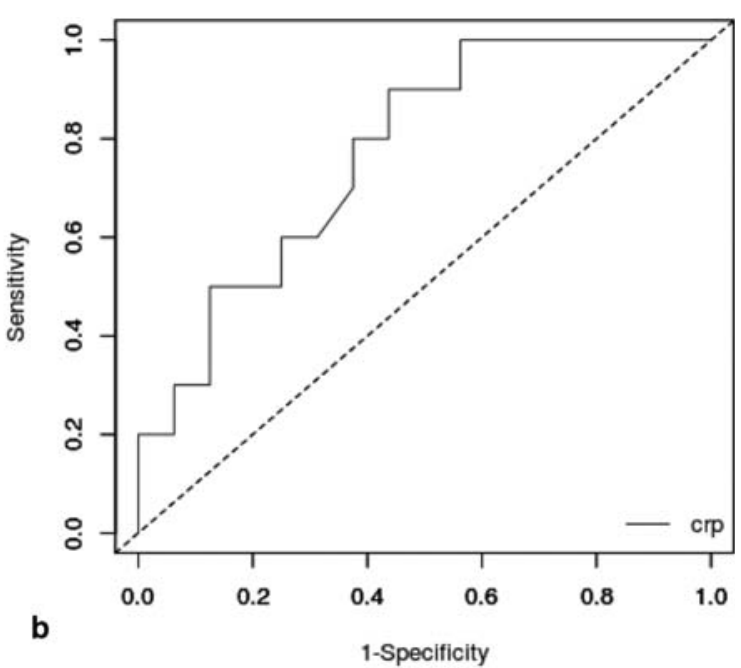

1-Specificity

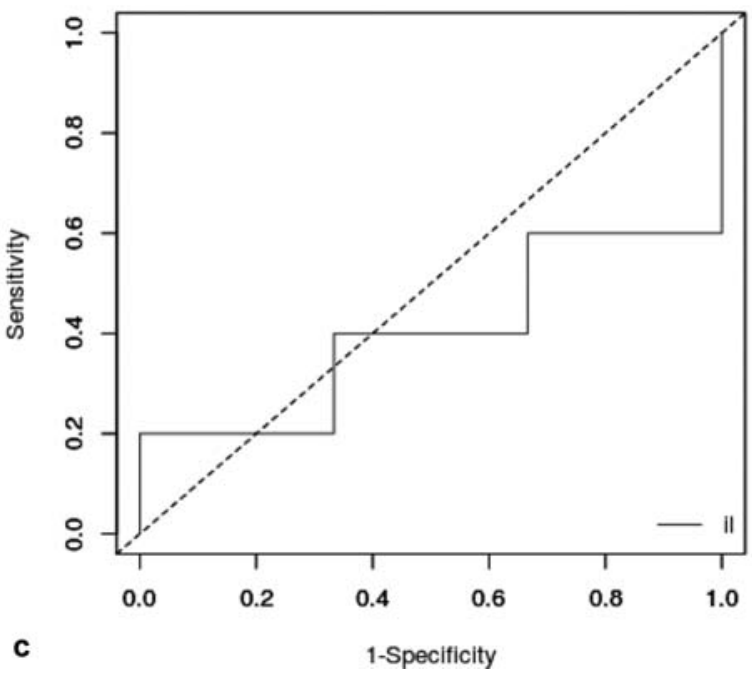

Fig. 3 Receiver-operating characteristics curve for discriminating between Rhinovirus pneumonia alone and Rhinovirus pneumonia with coinfections for (a) PCT, (b) hs-CRP, and (c) IL-6 on the initial hospital visit. Abbreviations: hs-CRP, high-sensitivity C-reactive protein; IL-6, Interleukin-6; PCT, procalcitonin.

Table 2 Accuracy of diagnostic parameters

\begin{tabular}{|l|l|l|l|}
\hline & PCT $>2.30 \mathrm{ng} / \mathrm{mL}$ & IL-6 $441.5 \mathrm{pg} / \mathrm{mL}$ & Hs-CRP $>1.53 \mathrm{mg} / \mathrm{dl}$ \\
\hline Sensitivity & $0.50(0.19-0.81)$ & $0.20(0.005-0.72)$ & $0.90(0.56-1.00)$ \\
\hline Specificity & $0.94(0.70-1.00)$ & $1.00(0.54-\mathrm{NaN})$ & $0.56(0.30-0.80)$ \\
\hline PPV & $0.83(0.44-0.96)$ & $1.00(0.16-1.00)$ & $0.56(0.30-0.98)$ \\
\hline NPV & $0.75(0.41-0.99)$ & $0.60(0.03-\mathrm{NaN})$ & $0.90(0.56-0.97)$ \\
\hline LR+ & $8.00(1.09-58.90)$ & - & $2.06(1.14-3.72)$ \\
\hline LR- & $0.53(0.28-1.00)$ & $0.80(0.52-1.24)$ & $0.18(0.03-1.20)$ \\
\hline Accuracy & $69.2 \%$ & $54.5 \%$ & $65.4 \%$ \\
\hline
\end{tabular}

Abbreviations: hs-CRP, high-sensitivity C-reactive protein; IL-6, Interleukin-6; LR +, positive likelihood ratio; LR - , negative likelihood ratio; NPV, negative predictive value; PCT, procalcitonin; PPV, positive predictive value

Although there are differences in cutoff points, it is undeniable that the diagnostic value of PCT presented in previous studies is relatively high. The heterogeneity among these studies can explain differences in critical values. Children with pneumonia caused by different viruses and bacteria may need to have diagnostic values of different biomarkers. Moreover, the severity of illness (severe or mild) can also affect the PCT index. Our research results also show that PCT has the highest accuracy rate of among biological markers, followed by hs-CRP. This finding is consistent with previously published data. ${ }^{18,20,41-44}$ 
Thus, in emergency cases, diagnostic thresholds, including serum PCT concentrations above $2.3 \mathrm{ng} / \mathrm{mL}$ and hs-CRP concentrations above 1.53 , may be used to detect bacterial infections in pediatrics with Rhinovirus severe pneumonia. Therefore, the development of rapid PCT and hs-CRP tests, and the extensive review of these tests are necessary and important to control severe Rhinovirus pneumonia in children.

Our research has some limitations. First, the small sample size and the study subjects selected by convenient sampling methods reduced the representativeness and generalization of the results. Second, the limitation of a cross-sectional study design is that it is not possible to identify the causative agent accurately. As the bacterial culture has low-sensitivity, the failure to find a bacterium after the culture is not sufficient to conclude the absence of that bacterium. In contrast, the detection of a well-developed colony is not adequate to conclude that it is the cause of the disease. Besides, the determination of a viral infection based on a positive serological test does not rule out the possibility of bacterial coinfection.

In some cases, one may see an unspecific increase in IgG/IgM in the inflammatory response. Therefore, the use of biomarkers such as PCT or CRP with the above cutoff recommendations is necessary to support the decision of whether to use antibiotics. Recently, it has been suggested that decision-making regarding antibiotic use based on PCT levels should not be used solely at hospital admission. However, there has been some opinion that making decisions about the use of antibiotics based on PCT concentration should not rely solely on PCT levels when hospitalized. ${ }^{45,46}$

\section{Conclusion}

This study highlights that inflammatory biomarkers such as PCT and hs-CRP can distinguish children with severe pneumonia caused by Rhinovirus alone and coinfected Rhinovirus. This result can assist clinicians in making decisions about appropriate antibiotic use.

\section{Conflicts of Interest}

None declared.

\section{References}

1 Jartti T, Lehtinen P, Vuorinen T, Ruuskanen O. Bronchiolitis: age and previous wheezing episodes are linked to viral etiology and atopic characteristics. Pediatr Infect Dis J 2009;28(04): 311-317

2 Bhuyan GS, Hossain MA, Sarker SK, et al. Bacterial and viral pathogen spectra of acute respiratory infections in under-5 children in hospital settings in Dhaka city. PLoS One 2017;12 (03):e0174488-e0174488

3 Müller L, Mack I, Tapparel C, et al. Human rhinovirus types and association with respiratory symptoms during the first year of life. Pediatr Infect Dis J 2015;34(08):907-909

4 Byington CL, Ampofo K, Stockmann C, et al. Community surveillance of respiratory viruses among families in the Utah Better Identification of Germs-Longitudinal Viral Epidemiology (BIGLoVE) Study. Clin Infect Dis 2015;61(08):1217-1224

5 Schilder AGM, Chonmaitree T, Cripps AW, et al. Otitis media. Nat Rev Dis Primers 2016;2(01):16063-16063
6 Meissner HC. Viral bronchiolitis in children. N Engl J Med 2016; 374(01):62-72

7 Jacobs SE, Lamson DM, St George K, Walsh TJ. Human rhinoviruses. Clin Microbiol Rev 2013;26(01):135-162

8 Hai T, Bich VTN, Ngai K, et al. Fatal respiratory infections associated with rhinovirus outbreak, Vietnam. Emerg Infect Dis 2012;18(11): 1886-1888

9 Iwane MK, Prill MM, Lu X, et al. Human rhinovirus species associated with hospitalizations for acute respiratory illness in young US children. J Infect Dis 2011;204(11):1702-1710

10 Toivonen L, Schuez-Havupalo L, Karppinen S, et al. Disease burden caused by rhinovirus infections during the first two years of life. Open Forum Infect Dis 2015;2(01):517

11 Fine J, Bray-Aschenbrenner A, Williams H, Buchanan P, Werner J. The resource burden of infections with rhinovirus/enterovirus, influenza, and respiratory syncytial virus in children. Clin Pediatr (Phila) 2019;58(02):177-184

12 MacBean V, Drysdale SB, Yarzi MN, Peacock JL, Rafferty GF, Greenough A. Respiratory viral infections in infancy and school age respiratory outcomes and healthcare costs. Pediatr Pulmonol 2018;53(03):342-348

13 Jung HS, Kang BJ, Ra SW, et al. Elucidation of bacterial pneumoniacausing pathogens in patients with respiratory viral infection. Tuberc Respir Dis (Seoul) 2017;80(04):358-367

14 Wark PA, Tooze M, Powell H, Parsons K. Viral and bacterial infection in acute asthma and chronic obstructive pulmonary disease increases the risk of readmission. Respirology 2013;18(06):996-1002

15 Van-Tam J., Sellwood C. Pandemic Influenza. CABI, 2nd ed, 2012. (Chap 1): 1-8

16 Rodrigues CMC, Groves H. Community-Acquired Pneumonia in Children: the Challenges of Microbiological Diagnosis. J Clin Microbiol 2018;56(03):e01318-17

17 Klig JE. Office pediatrics: current perspectives on the outpatient evaluation and management of lower respiratory infections in children. Curr Opin Pediatr 2006;18(01):71-76

18 Thomas J, Pociute A, Kevalas R, Malinauskas M, Jankauskaite L. Blood biomarkers differentiating viral versus bacterial pneumonia aetiology: a literature review. Ital J Pediatr 2020;46(01):4-4

19 Harris M, Clark J, Coote N, et al; British Thoracic Society Standards of Care Committee. British Thoracic Society guidelines for the management of community acquired pneumonia in children: update 2011. Thorax 2011;66(Suppl 2):ii1-ii23

20 Esposito S, Di Gangi M, Cardinale F, et al; Ita-CAP Study Group. Sensitivity and specificity of soluble triggering receptor expressed on myeloid cells-1, midregional proatrial natriuretic peptide and midregional proadrenomedullin for distinguishing etiology and to assess severity in community-acquired pneumonia. PLoS One 2016;11(11):e0163262-e0163262

21 Naydenova E, Tsanas A, Howie S, Casals-Pascual C, De Vos M. The power of data mining in diagnosis of childhood pneumonia. J R Soc Interface 2016;13(120):20160266

22 Zhu F, Jiang Z, Li WH, Wei HY, Su GD. Clinical significance of serum procalcitonin level monitoring on early diagnosis of severe pneumonia on children. Eur Rev Med Pharmacol Sci 2015;19(22):4300-4303

23 Baumann P, Baer G, Bonhoeffer J, et al. Procalcitonin for diagnostics and treatment decisions in pediatric lower respiratory tract infections. Front Pediatr 2017;5:183-183

24 Ho NT, Thompson C, Nhan LNT, et al. Retrospective analysis assessing the spatial and temporal distribution of paediatric acute respiratory tract infections in Ho Chi Minh City, Vietnam. BMJ Open 2018;8(01):e016349

25 World Health Organization, Guidelines for The Management of Common Childhood Illnesses. World Health Organization, Pham Ngoc Thach's University of Medicine. 2nd ed. 2013

26 Hartiala M, Lahti E, Forsström V, VuorinenT, Ruuskanen O, Peltola V. Characteristics of hospitalized rhinovirus-associated communityacquired pneumonia in children, Finland, 2003-2014. Front Med (Lausanne) 2019;6:235-235 
27 Rambaud-Althaus C, Althaus F, Genton B, D’Acremont V. Clinical features for diagnosis of pneumonia in children younger than 5 years: a systematic review and meta-analysis. Lancet Infect Dis 2015;15(04):439-450

28 Thompson M, Coad N, Harnden A, Mayon-White R, Perera R, Mant D. How well do vital signs identify children with serious infections in paediatric emergency care? Arch Dis Child 2009;94(11):888-893

29 Salah ET, Ahmed E, Elhussien M, Salah T. The use of vital signs as predictors for serious bacterial infections in children with acute febrile illness in a pediatric emergency setting in Sudan. Sudan J Paediatr 2014;14(02):35-40

30 Gou X, Yuan J, Wang H, et al. IL-6 during influenza-Streptococcus pneumoniae co-infected pneumonia-A protector. Front Immunol 2020;10:3102-3102

31 Karhu J, Ala-Kokko TI, Vuorinen T, Ohtonen P, Julkunen I, Syrjälä HT. Interleukin-5, interleukin-6, interferon induced protein-10, procalcitonin and C-reactive protein among mechanically ventilated severe community-acquired viral and bacterial pneumonia patients. Cytokine 2019;113:272-276

32 Esposito S, Bianchini S, Gambino M, et al. Measurement of lipocalin-2 and syndecan-4 levels to differentiate bacterial from viral infection in children with community-acquired pneumonia. BMC Pulm Med 2016;16(01):103-103

33 Bhuiyan MU, Blyth CC, West R, et al. Combination of clinical symptoms and blood biomarkers can improve discrimination between bacterial or viral community-acquired pneumonia in children. BMC Pulm Med 2019;19(01):71-71

34 Xu RY, Liu HW, Liu JL, Dong JH. Procalcitonin and C-reactive protein in urinary tract infection diagnosis. BMC Urol 2014;14:45

35 Zhou WF, Chen Q Jin MF, et al. The diagnostic accuracy of highmobility group box 1 protein and twelve other markers in discriminating bacterial, viral and co-infected bronchial pneumonia in Han children. Microbiol Immunol 2011;55(04):279-288

36 Elemraid MA, Rushton SP, Thomas MF, Spencer DA, Gennery AR, Clark JE. Utility of inflammatory markers in predicting the aetiology of pneumonia in children. Diagn Microbiol Infect Dis 2014;79(04):458-462

37 Berg AS, Inchley CS, Fjaerli HO, Leegaard TM, Lindbaek M, Nakstad B. Clinical features and inflammatory markers in pediatric pneumonia: a prospective study. Eur J Pediatr 2017;176(05):629-638

38 Virkki R, Juven T, Rikalainen H, Svedström E, Mertsola J, Ruuskanen O. Differentiation of bacterial and viral pneumonia in children. Thorax 2002;57(05):438-441

39 Jin M, Khan AI. Procalcitonin: uses in the clinical laboratory for the diagnosis of sepsis. Lab Med 2010;41(03):173-177

40 Hoshina T, Nanishi E, Kanno S, Nishio H, Kusuhara K, Hara T. The utility of biomarkers in differentiating bacterial from non-bacterial lower respiratory tract infection in hospitalized children: difference of the diagnostic performance between acute pneumonia and bronchitis. J Infect Chemother 2014;20(10):616-620

41 Lacour AG, Gervaix A, Zamora SA, et al. Procalcitonin, IL-6, IL-8, IL1 receptor antagonist and $C$-reactive protein as identificators of serious bacterial infections in children with fever without localising signs. Eur J Pediatr 2001;160(02):95-100

42 Moulin F, Raymond J, Lorrot M, et al. Procalcitonin in children admitted to hospital with community acquired pneumonia. Arch Dis Child 2001;84(04):332-336

43 Simon L, Gauvin F, Amre DK, Saint-Louis P, Lacroix J. Serum procalcitonin and C-reactive protein levels as markers of bacterial infection: a systematic review and meta-analysis. Clin Infect Dis 2004;39(02):206-217

44 Moulin F, Raymond J, Lorrot M, et al. Procalcitonin in children admitted to hospital with community acquired pneumonia. Arch Dis Child 2001;84(04):332-336

45 Boussekey N, Leroy O, Alfandari S, Devos P, Georges H, Guery B. Procalcitonin kinetics in the prognosis of severe communityacquired pneumonia. Intensive Care Med 2006;32(03):469-472

46 Christ-Crain M, Stolz D, Bingisser R, et al. Procalcitonin guidance of antibiotic therapy in community-acquired pneumonia: a randomized trial. Am J Respir Crit Care Med 2006;174(01):84-93 